\title{
Case report 476
}

Jeffrey M. Boorstein, M.D., and David L. Spizarny, M.D.

Department of Diagnostic Radiology, University of Michigan, Ann Arbor, Michigan, USA

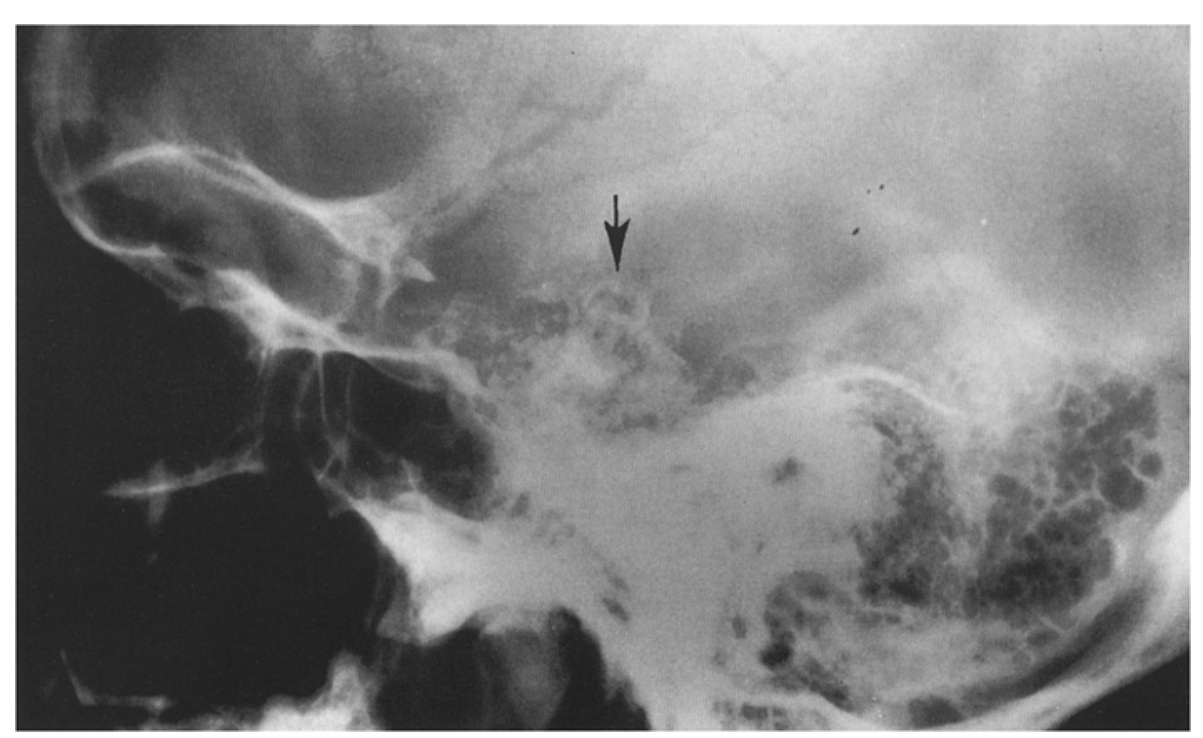

\section{Radiological studies}

Fig. 1. A lateral skull roentgenogram demonstrates a partially calcified parasellar mass (arrow) (Courtesy of W. Laidlaw, M.D., Blodgett Memorial Medical Center, East Grand Rapids, Michigan)

Address reprint requests to: David L. Spizarny, M.D., Department of Radiology, Taubman Center 2910A/0326, 1500 E. Medical Center Drive, Ann Arbor, MI 48109-0326, USA 

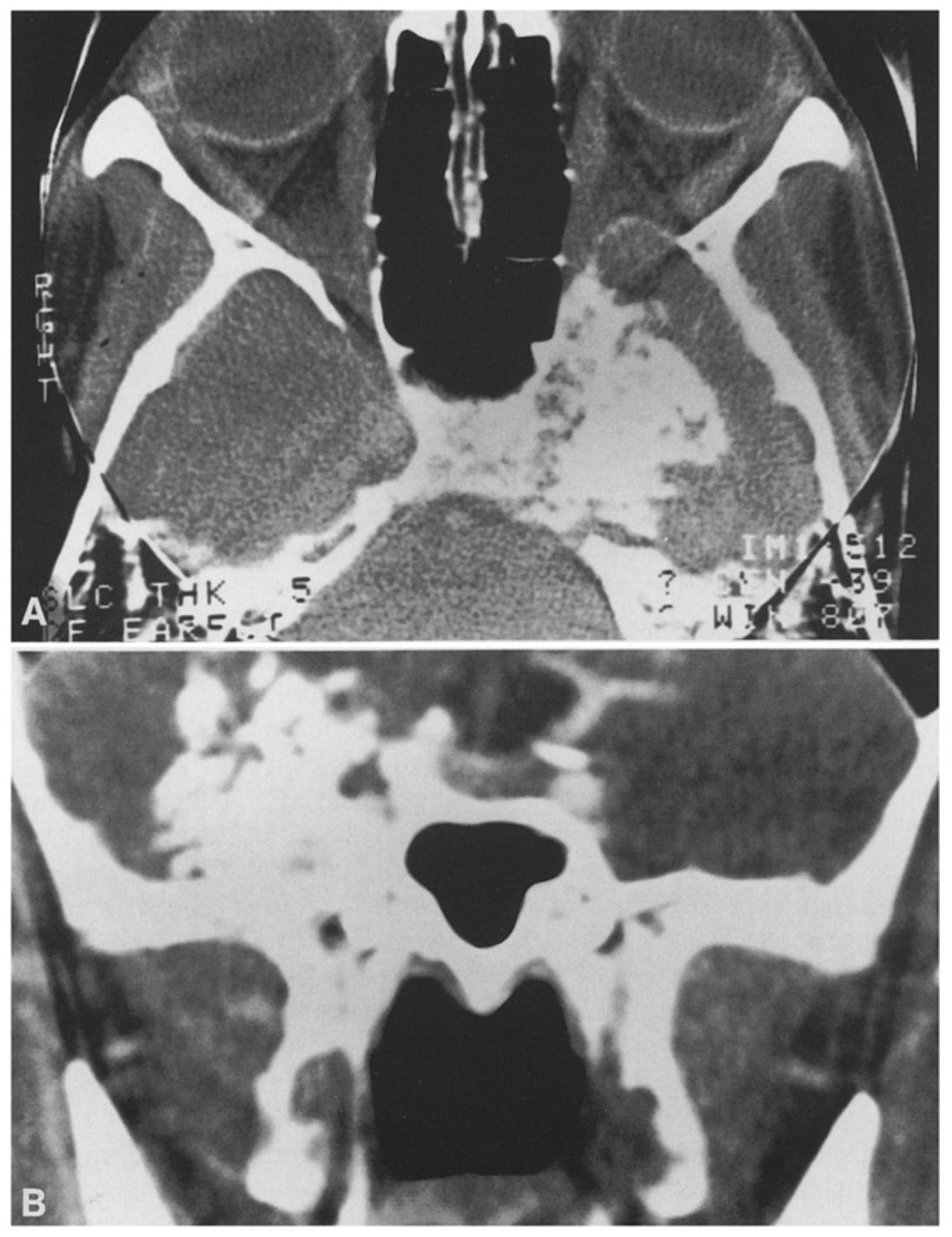

Fig. 2 A, B. Axial (A) and coronal (B) CT studies demonstrate a partially calcified left parasellar mass extending into the left middle fossa. The left sphenoid wing is eroded. (Courtesy of W. Laidlaw, M.D., Blodgett Memorial Medical Center, East Grand Rapids, Michigan)

\section{Clinical information}

This 29-year-old women was admitted to an outside hospital with a several months' history of numbness of the left cheek, decreasing vision in her left eye, and left ptosis. Physical examination demonstrated decreased left visual acuity, left temporal hemianopia, left proptosis, early left papilledema, and left first, third, fifth, and sixth cranial nerve palsies.
A lateral skull roentgenogram (Fig. 1) and computed tomography (CT) (Fig. 2) demonstrated a left partially calcified parasellar mass. Angiography revealed distortion and elevation of precavernous, cavernous, and supraclinoid left internal carotid artery. The left cavernous sinus was occluded. No tumor stain or tumor vessels were present. The mass was partially resected via a left temporal craniotomy. 


\section{Diagnosis: Chondrosarcoma of base of skull (CBS)}

The differential diagnosis includes osteochondroma, chordoma, and meningioma.

\section{Pathological findings}

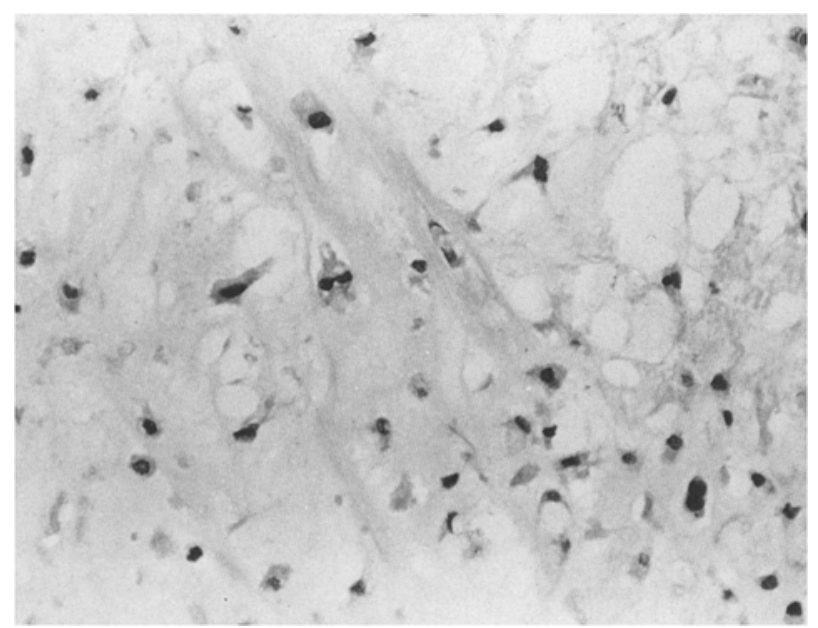

Fig. 3. Photomicrograph from surgical specimen. This field, from a cellular area of neoplasm, contains atypical chondrocytes in a thin matrix background. Nuclei are hyperchromatic and irregular, and binucleate cells are evident (hematoxylin and eosin, $\times 230$ ). (Courtesy of K. Grant, M.D., Blodgett Memorial Medical Center, East Grand Rapids, Michigan)

\section{Discussion}

The gross specimen consisted of multiple, irregular fragments of grey-white cartilaginous material, with admixed bits of bone. Microscopically, the fragments of bone were partly surfaced by irregularly lobulated, focally calcified cartilage, that appeared to erode the bony cortex focally. The appearance of the cartilage varied, with foci of low cellularity, "dense" chondroid matrix, areas of dense cellularity and "thin" chondroid matrix. In these latter areas, the chondrocytes appeared somewhat bizarre, with increased nucleus/cytoplasm ratio and hyperchromatic nuclei. Occasional chondrocytes were binucleate (Fig. 3).

Although osteochondroma was considered, the morphologic features in conjunction with clinical and roentgenographic manifestations were believed to be diagnostic of chondrosarcoma. Enlargement of an osteochondroma, especially in adults, suggests chondrosarcoma, and excision of tumor is indicated even if histological confirmation of malignancy is absent [1].

Chondrosarcoma of the base of the skull (CBS) is rare, representing less than $0.16 \%$ of all intracranial neoplasms and $6 \%$ of all lesions of the base of the skull [2]. These lesions may arise from embryonal rests of cartilaginous tissue during early development of the bony base, or from metaplasia of adjacent brain, dura, choroid, or arachnoid [3, 4]. CBS can occur at any age, with a peak incidence in the fourth and fifth decades of life. No sex predilection exists.

CBS is locally aggressive, and relatively slowly growing. Untreated, death may occur within five years of the onset of symptoms. Metastases are rare, but have been reported [5]; they occur with more aggressive chondrosarcoma. Local recurrence after surgical excision may occur even after extended periods of time.

As expected, the signs and symptoms of CBS depend upon location. Intracranial chondrosarcomas occur most frequently in the parasellar area, but have been described in the posterior fossa, in the cerebellopontine angle, and over the convexity of the cranium [4]. Presenting features include deficits in cranial nerve, headaches, nausea, paresis, seizures, and hypopituitarism [2].

The roentgenographic features of CBS include calcification on plain skull roentgenograms in greater than $60 \%$ of cases [6]. The calcification may be stippled, finely speckled, amorphous, or ring-like [7]. Axial and coronal CT, before and after intravenous contrast, help establish the diagnosis and define the extent of the tumor [2]. Calcification of tumor and bony destruction support the diagnosis of chondrosarcoma. Angiographically, chondrosarcoma is usually avascular and displaces normal vessels, although vascular CBS has been reported [8].

Although the broad differential diagnosis of CBS includes other tumors, the two lesions most difficult to differentiate from CBS are chordoma and meningioma [2]. CT with intravenous contrast will usually show confluent enhancement of meningioma, with only variable degrees of enhancement of chordoma and chondrosarcoma [4]. Cystic areas on $\mathrm{CT}$ occur occasionally with meningioma and rarely with chordoma or chondrosarcoma. Chordoma and chondrosarcoma usually cause lytic, skeletal lesions and usually are avascular, whereas meningiomas may demonstrate hyperostosis and generally are vascular. Finally, chordoma is generally midline, while chondrosarcoma is frequently parasellar [2].

Grossly, chondrosarcomas are shiny gray or blue-gray. They are termed primary if they arise 
from normal bone, secondary if they arise from pre-existing cartilaginous lesions, central if they arise from the interior of bone, and peripheral if they arise from the surface. Histologically, the traditional, low-grade, slowly growing chondrosarcoma is comprised of cartilaginous cells with hyperchromatic, multilobate and grotesque nuclei, mitotic figures, multinucleate giant cells and calcification [9]. Mesenchymal chondrosarcoma, first described by Lichtenstein and Bernstein [10], is extremely rare, is most common between the ages of 10 and 40 years, is usually peripheral, and has a high propensity for hematogenous metastasis. Clear-cell chondrosarcoma, the rarest variant, is more common in men and is predominately peripheral [11]. Finally, low-grade chondrosarcomas may dedifferentiate into highly aggressive anaplastic sarcomas, known as dedifferentiated chondrosarcoma [11, 12]. This lesion is one of the most lethal bone tumors known, with frequent and early metastases.

The treatment of CBS is surgical excision, as this lesion is predominately radioresistant and chemoresistant [13]. Post-operative radiation therapy has been utilized for surgically inaccessable lesions or incomplete resections $[2,11,14]$.

Two years after the diagnosis was established the patient presented with recurrent severe headaches, nausea, vomiting, and confusion. Physical examination was unchanged, except that the left visual field loss was almost complete. Skull roentgenograms and CT demonstrated a recurrent mass, and a ventriculo-peritoneal shunt was placed.

In summary, focal neurologic findings in a 29-year-old woman were secondary to a mass at the skull base. Skull roentgenograms and CT localized a partially calcified, non-enhancing, left parasellar mass, which was partially resected. Two years later the patient presented with similar symptoms and locally recurrent mass. Oseochondroma was originally considered; however, tumor recurrence, radiographic manifestations, and morpho- logic features were felt more consistent with chondrosarcoma. This patient illustrates that diagnosis of low grade chondrosarcoma requires cooperation between skeletal radiologist, skeletal pathologist, and surgeon.

Acknowledgement. We wish to thank Gerald D. Abrams, M.D., Department of Pathology, University of Michigan, Ann Arbor, Michigan, for his interpretation of the pathological findings.

\section{References}

1. Murray RO, Jacobson HG (1977) The radiology of skeletal disorders, 2nd edn. Churchill Livingstone, Edinburgh London New York

2. Grossman RI, Davis KR (1981) Cranial computed tomographic appearance of chondrosarcoma of the base of the skull. Radiology 141:403

3. Minagi H, Newton TH (1969) Cartilaginous tumors of the base of the skull. AJR 105:308

4. Bahr AL, Gayler BW (1977) Cranial chondrosarcomas. Radiology, 124:151

5. Leedham PW, Swash M (1972) Chondrosarcoma with Subarachnoid Dissemination. J Pathol 107:59

6. Greenfield GB (1980) Radiology of bone diseases, 3rd ed., Lippincott, Philadelphia, p 540

7. Pribram HW (1971) The skull. In: Newton TH, Potts DG (eds) Radiology of the skull and brain, Vol, 1. Mosby, St. Louis, p 396

8. El-Gindi S, Abd-el-Hafeez M, Salama M (1974) Extracranial skeletal metastases from an intracranial meningeal chondrosarcoma. J Neurosurg 40:651

9. Erlandson RA, Hyvos AG (1974) Chondrosarcoma: a light and electron microscopic study. Cancer 34:1642

10. Lichtenstein L, Bernstein D (1959) Unusual benign and malignant chondroid tumors of bone: a survey of some mesenchymal cartilaginous tumors and malignant chondroblastic tumors, including a few multicenter ones, as well as many atypical benign chondroblastomas and chondromyxoid fibromas. Cancer 12:1142

11. McLeod RA (1986) Chondrosarcoma. In: Taveras JM, Ferrucci JT (eds) Radiology: Diagnosis-Imaging-Intervention, Vol. 5. Lippincott, Philadelphia

12. Kahn LB (1976) Chondrosarcoma with dedifferentiated foci: a comparative and ultrastructural study. Cancer $37: 1365$

13. Lindbom A, Soderberg G, Spjut HJ (1961) Primary chondrosarcoma of bone. Acta Radiol [Stockh] 55:81

14. Gay I, Elidan J, Kopolovic J (1981) Chondrosarcoma at the skull base. Ann Otol Rhinol Laryngol 90:53 